\title{
QUALITY ASSURAANCE EVALUATION FOR HIGHER EDUCATION INSTITUTIONS USING STATISTICAL MODELS
}

\author{
Murtadha M. Hamad ${ }^{1}$ and Shumos T. Hammadi ${ }^{1}$ \\ ${ }^{1}$ Faculty of Computers, Department of Computer Science, Al-Anbar University,Iraq \\ mortadha61@yahoo.com and sun_algoldeyahoo.com
}

\begin{abstract}
This research aims to evaluate the institutions of higher education based on comprehensive quality standards that have been developed for each member of teaching in higher education institutions. Adopted this research on five key elements for the evaluation of faculty members, this formula adopted by the standard model to evaluate faculty members. The focus was on scientific performance in the first place and the put a higher rate because it is the main focus of the evaluation of faculty, as well as the efficiency of teaching. putless proportion of the educational performance and the relationship to the administration because they are linked not many the evaluation, as a teaching and scientific performance. Model includes the development of scientific performance by $35 \%$, the efficiency of teaching status to $25 \%$, development of educational performance by 10\%, development of personal behaviour by 20\%, and the relationship management mode by 10\%, so that the sum of these themes will be $100 \%$.

Applied this formula on a sample of members of the teaching, so that formed a large database evaluations of faculty members.

Analyzed the data obtained by using an algorithm proposed evaluation, which relied primarily on statistical analysis, statistical functions adopted to evaluate each college according to formula set forth.
\end{abstract}

\section{Keywords}

Quality Assurance, statistical Models, Higher Education, Evaluation, coefficient of variation.

\section{Introduction}

Quality in the sense of achieving academic excellence has always been a central value in higher education" [1]. Institutions of higher education have their beginning relied on the reputation of their faculties to attract students and scholars and to give credibility to their degree programs, their graduates, and their researches.

However, the way Quality Assurance's key components, Accreditation and Evaluation or Assessment, are defined has a great influence on its implementation and impact. Assessment is about language regarding the nature of teaching, learning, and appropriate inquiry and power regarding how higher education is organized and rewarded.

The first is academic peer-review-based Accreditation, the second is governmental oversight, the third includes the Scientific Education and Management Movements, and the fourth is the Accountability movement. Unless these different traditions and their related language and power implications are clearly understood and addressed [2].

The quality issue turn in Central and East-European (CEE) countries, signifying the formation of higher education Quality Assurance (QA) policies in view of the transition from elite higher education to mass higher education, was marked by influences from outside the region [3].

DOI: $10.5121 / \mathrm{ijdms} .2011 .3308$ 
International Journal of Database Management Systems ( IJDMS ), Vol.3, No.3, August 2011

There is identified five broad approaches for defining quality in higher education. These are (i) quality meaning exceptional, where quality is related to conception of excellence; (ii) quality meaning perfection, where quality has consistent and error-free attributes; (iii) quality meaning fit for purpose, where quality fulfils the perceived requirements of stakeholders; (iv) quality meaning value for money; and (v) quality meaning transformation, i.e. quality necessarily involves a change from a current to an ideal end state [4].

The Technical Working Group "Quality in Vocational Education and Training" of the European Commission has developed a Common Quality Assurance Framework (CQAF) for Vocational Education and Training (VET) aimed at supporting VET providers in the development, evaluation and improvement of QA systems and practices throughout Europe. The QA model presented in the CQAF includes four phases[5,6]:

1. planning (setting goals);

2. implementation (of actions to achieve the goals set);

3. evaluation and assessment (evaluation of programmer provision by objectives, and assessing the achieved outcomes);

4. review, e.g. the discussion of the results of quality assessments among end users, detecting causes of underperformance, and translating the conclusions into improvement actions.

Traditional governmental mechanisms for QA of higher education are no longer meaningful in most transition countries Emerging markets have demanded new skills, which requires that tertiary institutions develop new forms of higher education [7].

\section{Related Work}

Several researchers in the field of Quality Assurance Evaluation. There are a number of researchers and scientists used the methods of modeling technique based on the mathematical technique for evaluation to ensure the quality of the assessment. Some of these researches are summarized below:

Enshun Tian, With the progress of globalization of the world economy and internationalization of higher education, both internal and external factors may influence the direction of higher education reform. The of higher education by far has shown a clear tendency :more partners, including government, institution of higher education and society, participate in QA and make policies which can respect their needs and interests of higher education, and a balance between autonomy and accountability is expected to be reached. For China, the reform is essential, and it should be aimed to establish a system of QA in which the universities independently guarantee their own quality, the government is in charge of macroscopic management, the society participate in the supervision, and the market adjustment functions spontaneously[8].

Darwin D. Hendel and Darrell R. Lewis, One issue facing countries in transition concerns how to ensure quality for a broader and more diverse set of institutions. QA processes i.e. accreditation, accountability and assessment) have particular relevance today as higher education undergoes dramatic changes in countries in transition, as the world becomes more internationalized, and as private higher education institutions increase in number and enrol increasing numbers of students. Three questions emerge. Do differences among transition countries relative to central control prior to independence explain the current set of QA mechanisms? Has the growth of private higher education in transition countries affected how QA is conceptualized? Have QA mechanisms been affected by the opening of branch campuses in transition countries?[7].

Karoline Hollander, The aim of this paper is to present the experience of doctoral candidates and junior researchers with standardization of procedures and processes in doctoral education and 
International Journal of Database Management Systems ( IJDMS ), Vol.3, No.3, August 2011

thereby illustrate the key factors in ensuring quality. However, these key factors are making the process of QA in doctoral education difficult, because a standardization at doctoral level is even more demanding than at bachelor and master levels[9].

Ephraim Mhlanga, QA is increasingly becoming an important aspect of higher education institutions in developing countries, as expressed in the development of relevant policies, structures and systems at national and institutional levels. This thesis critically examines the nature of QA policies and practices in selected universities in the Southern African Development Community (SADC), as well as the factors that shape these policies. Through a close examination of these policies and practices, the thesis explains why some universities realize better quality than others, even though they fall within the same geographical region and share relatively similar historical legacies[10].

Rizwan Akram Rana and Prof. Norman Reid, QA in higher education is a mess: the problem of quality is embedded in complex set of interacting issues that are the concern to many and varied stakeholders. The major aim of this paper was to point out the world-wide education reforms, paradigms and theories for assuring quality in higher education and to discus and suggest appropriate and most relevant strategies, indicators and models of QA system in higher education for Pakistan[4].

\section{Defining Quality Assurance in Education}

Quality is often described as the totality of features and characteristics of a service that bear on its ability to satisfy stated or implied needs. Quality in higher education, according to Article 11 of the World Declaration on Higher Education published by the United Nations, is a multidimensional concept, which should embrace all its functions and activities: teaching and academic programmers, research and scholarship, staffing, students, buildings, faculties, equipment, services the community and the academic environment. It should take the form of internal self-evaluation and external review, conducted openly by independent specialists, if possible with international expertise, which are vital for enhancing quality. Independent national bodies should be established and comparative standards of quality, recognized at international level, should be defined. Due attention should be paid to the specific institutional, national and regional contexts in order to take into account diversity and to avoid uniformity.

Quality also requires that higher education should be characterized by its international dimension: exchange of knowledge, interactive networking, mobility of teachers and students, and international research projects, while taking into account the national cultural values and circumstances [11, 12]. For any higher education institution, there are several aspects of reputation which are important [11]:

- It is built upon the competitive elements of quality, reliability, delivery, history and price, of which quality has become strategically the most important.

- Once a higher education institution acquires a poor reputation for quality, it takes a very long time to change it.

- Higher education reputations, good or bad, can quickly become national reputations.

- The management of the competitive weapons, such as quality, can be learned like any other skill, and used to turn round a poor reputation, in time.

Quality is often used to signify "excellence" of a product or service people talk about "Harvard top quality" [13]. In some manufacturing companies the word may be used to indicate that a piece of material or equipment conforms to certain physical dimensional characteristics often set down in the form of a particularly tight specification. If we are to define quality in a way that is useful in its management, then must recognize the need to include in the assessment of quality the true requirements of the "customer" - the needs and expectations[14]. 
International Journal of Database Management Systems ( IJDMS ), Vol.3, No.3, August 2011

\section{Effect of Evaluation on Quality}

Lack of community confidence and rapid increase in the participation rates, set in train a trend by the governments in the late 1980s to device ways of formally evaluating the performance of Higher Education. The movement for evaluation, came under the strong influence of the QA movement which was sweeping the industry at that time. Many of the terminology and practices of QA were applied to the evaluation process as well.

Invariably, all funding agencies acknowledge the need for autonomy of the institutions in order to perform effectively in their own circumstances. At the same time there is also the need for measures to evaluate the performance (i.e. the accountability) of the institution. Within these parameters the evaluating agencies tend to adopt a number of different approaches to monitoring quality in higher education. In general, they can all be described as forms of external scrutiny conditioned by the prevailing political scene.

At the root (the) governments around the world are looking for higher education to be more responsive, including[15]:

Making education more relevant to social and economic needs,

- Widening access to higher education,

- Expanding numbers, usually in the face of decreasing unit cost, and

- Ensuring comparability of provisions between institutions.'

\section{Data Quality Assessment ( DQA) and the Data Life Cycle}

The data life cycle depicted in Figurel comprises three steps: planning, implementation, and assessment. During the planning phase, a systematic planning procedure (such as the Data Quality Objectives (DQO) Process) is used to define criteria for determining the number, location, and timing of samples (measurements) to be collected in order to produce a result with a desired level of certainty.

This information, along with the sampling methods, analytical procedures, and appropriate QA and quality control procedures, is documented in the QA Project Plan. Data are then collected following the QA Project Plan specifications in the implementation phase.

At the outset of the assessment phase, the data are verified and validated to ensure that the sampling and analysis protocols specified in the QA Project Plan were followed, and that the measurement systems were performed in accordance with the criteria specified in the QA Project Plan. Then the statistical component of DQA completes the data life cycle by providing the evaluation needed to determine if the performance and acceptance criteria developed by the DQO planning process were achieved [16]. 


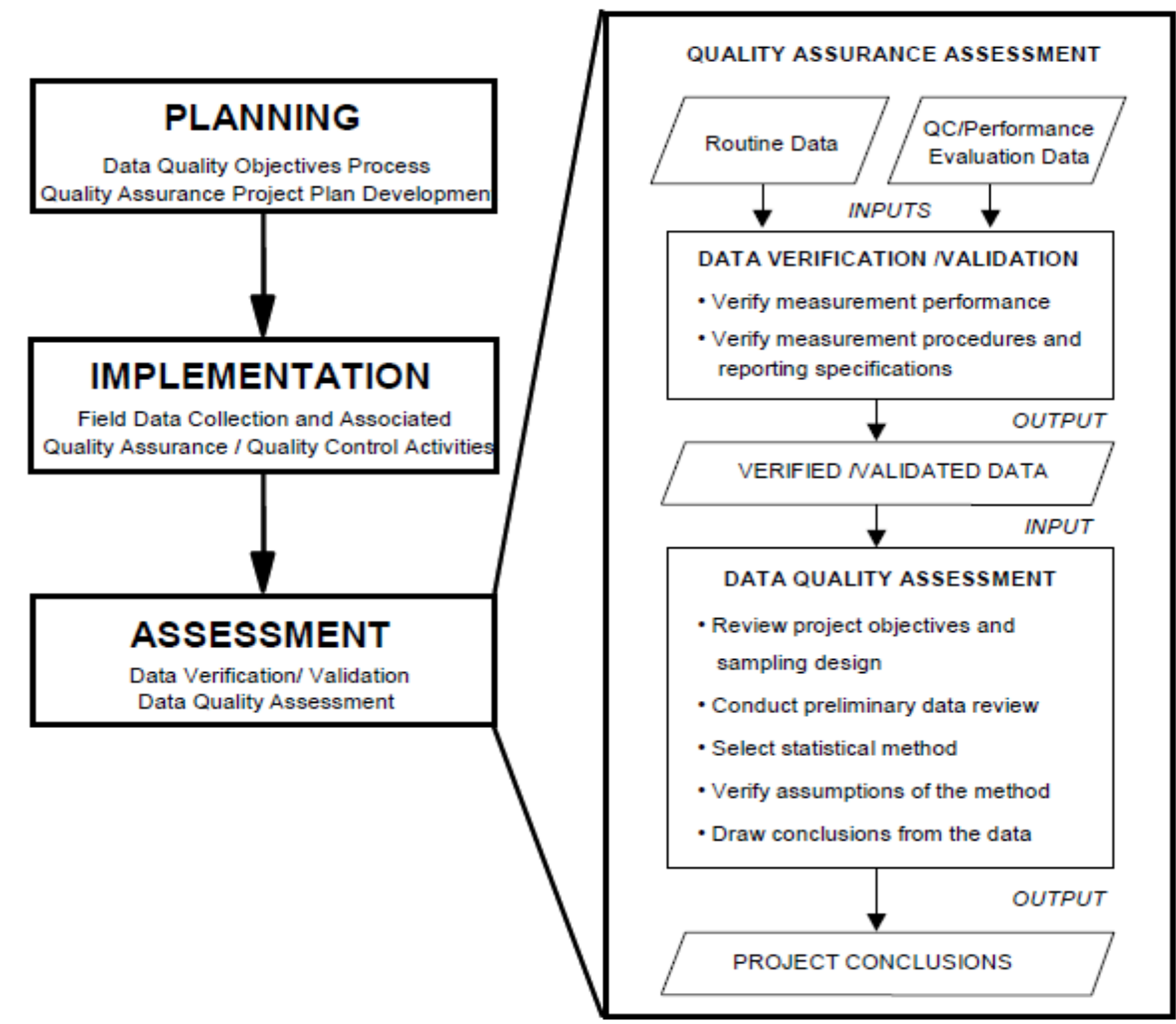

Figure 1. Data Life Cycle

\section{Standard Models}

Many QA standards and models exist with a large number of choices. "there are more than 300 standards developed and maintained by more than 50 different organizations." Popular models are the ISO 9001, which specifies requirements for a quality management system within an organization and the Software Engineering Institute (SEI) Capability Maturity Model (CMM), which provides a framework for continuous software process improvement, although many others are used, depending on user goals. The key notion is that they provide guidelines for conducting audits, testing activities, and for process improvement. The CMM approach classifies the maturity of the software organization and practices into five levels describing an evolutionary process from chaos to discipline[17]:

Level 1: Initial. The software process is characterized as ad hoc, and occasionally even chaotic. Few processes are defined, and success depends on individual effort and heroics.

Level 2: Repeatable. Basic project management processes are established to track cost, schedule, and functionality. The necessary process discipline is in place to repeat earlier successes on projects with similar applications.

Level 3: Defined. The software process for both management and engineering activities is documented, standardized, and integrated into a standard software process for the organization. All projects use an approved, tailored version of the organization's standard software process for developing and maintaining software.

Level 4: Managed. Detailed measures of the software process and product quality are collected. Both the software process and products are quantitatively understood and controlled.

Level 5: Optimizing. Continuous process improvement is enabled by quantitative feedback from the process and from piloting innovative ideas and technologies. 
International Journal of Database Management Systems ( IJDMS ), Vol.3, No.3, August 2011

The challenge for many Mathematical Programming (MP) vendors is to move from Level 1, the chaotic, creative and exciting phase to Level 5 without losing creativity and, most importantly, to stay in business.

\section{Modeling Techniques}

The proper application of statistical techniques to data production and analysis is of paramount importance. Because the statistical techniques most useful for evaluating data are well known to many analysts, only several of those most frequently used will be reviewed briefly here.

\subsection{The Arithmetic Mean}

The Arithmetic Mean of a collection of a numerical values is the sum of these values divided by the number of value.

Equation (1) is used to calculate the arithmetic mean[18].

$$
\bar{x}=\frac{\sum_{i=1}^{n} x_{i}}{n}
$$

$n$

Where $n$ is the sample size.

$$
\sum_{i=1}^{n} x_{i}=\text { Sum of all the measurements in the sample of size } n
$$

The arithmetic mean is also called mean or average.

Geometrically, the mean of a frequency distribution represents the center of gravity. If the frequency curve is considered as a plate of some kind. It will balance at the mean[19].

\subsection{The Standard Deviation}

There is a practical difficulty associated with using the variance, that is the units in which the variance is expressed are not the same as the observations. That because the deviation have been squared. This means that if the grads of students are considered, the unit of variance is (point $)^{2}$. To correct this inadequacy and obtain a measure of dispersion for the grads, which will be in term "points", the square root of the variance is taken. The square root of the variance is called the standard deviation of the variable $x$, it is denoted symbolically by $\mathrm{S}[19]$.

$$
s=\sqrt{\frac{\sum_{i=1}^{n}\left(x_{i}-\bar{x}\right)^{2}}{n-1}}
$$

Where $\mathrm{n}$ is the sample size.

\subsection{The variance}

The arithmetic mean (or average) of the squared deviation $\left(x_{i}-\bar{x}\right)^{2}$ is called the variance. The variance denoted symbolically by $s^{2}$ [19].

Its formula is :

$$
s^{2}=\frac{\sum_{i=1}^{n}\left(x_{i}-\bar{x}\right)^{2}}{n-1}
$$




\subsection{Coefficient of Variation}

One disadvantage of the standard deviation as a measure of variation is that it depends on the units of measurement. For instance, the weights of certain objects may have a standard deviation of 0.1 ounce 2.85 milligrams ( which is the same ), but neither value really tells us whether it reflects a greater deal of variation or very little variation. If the objects we are weighting are the eggs of small birds, either figure would reflect a great deal of variation, but this would not be the case if the objects we are weighting are 100-pound bags of potatoes. What we need in situation like this is a measure of relative variation, such as the coefficient of variation [19].

The coefficient of variation for a data collection expresses the standard deviation as a percentage of the mean. The coefficient of variation indicates the relative amount of variability in a distribution. The coefficient of variation is used by decision maker to compare the variability of two or more distribution .

To bring this idea out explicitly, the coefficient of variation, of a distribution, is define as :

$C \cdot V=\frac{S}{\bar{X}} x 100$

When using the coefficient of variation, the dispersion of the different frequency distribution can be compared.

\section{Proposed Algorithm For Evaluation}

\section{Input:}

- DB for each college.

Ratios used for each axis

- The performance of scientific and put his $35 \%$.

- The efficiency of teaching by $25 \%$.

- Educational performance by $10 \%$.

- Personal Conduct by $20 \%$.

- Relationship management by $10 \%$.

Output:

- A report for the assessment of higher education institutions.

Step1: Extract evaluation of each college by the statistical analysis.

$$
\begin{aligned}
& I=0 \\
& \text { While }(I<n) \\
& \text { Begin } \\
& \text { Select the college }(i) \\
& \text { For } i=1 \text { to } 6 \\
& \text { Begin } \\
& \text { Read axis }(i) \text { for each Prof. } \\
& \text { Apply the standards (statistical models) } \\
& \text { End for } \\
& I=i+1 \\
& \text { end While }
\end{aligned}
$$

Step2: Find a final evaluation of the University Depending on the results of formula. 


\section{Experimental Results}

Implementation of the algorithm proposed evaluation data on faculty stock database Appendix A, using statistical analysis of these data. Where take a sample from the faculties of the University of Anbar, and had the statistical analysis. In this paper, evaluated three colleges scientific and humanitarian three faculties of the University of Anbar, then compare the scientific colleges with colleges of humanity to find the most homogeneous colleges using the function coefficient of variation $(\mathrm{COV})$.

See appendix A include some sections of code used to implement the algorithm.

In the Table 1 notes the number of evaluations of faculty members in accordance with QA standards adopted for each teaching: the scientific performance, efficiency of teaching, educational performance, personal conduct, relationship management, the evaluation found using the law of the final percentage depending on the rates set for each axis. And then find a final evaluation for each college, depending on the final grade for the assessment found that of the total assessment of five aspects. After evaluating all the college and found the difference between science faculties and colleges to find out any humanitarian colleges more homogeneous.

The following Table 2 and Table 3 shows the coefficient of variation(COV) between the two sections of scientific and humanitarian. also applied for each axis then applied to the value resulting from the final Total University the axes.

Table 1. Evaluation ratios

\begin{tabular}{|l|cccccc|}
\hline colleges & $\begin{array}{c}\text { Perf. } \\
\text { scientifi }\end{array}$ & $\begin{array}{c}\text { Effici. } \\
\text { teaching }\end{array}$ & $\begin{array}{c}\text { Edu. } \\
\text { performanc }\end{array}$ & $\begin{array}{c}\text { Personal } \\
\text { behavior }\end{array}$ & $\begin{array}{c}\text { Relatio. } \\
\text { management }\end{array}$ & $\begin{array}{c}\text { Final } \\
\text { evaluation }\end{array}$ \\
\hline Computer & 72.653 & 81.142 & 79.523 & 83.33 & 79.047 & 78.238 \\
\hline Science & 55.33 & 82.533 & 92.33 & 93.33 & 91.33 & 77.033 \\
\hline $\begin{array}{l}\text { Veterinary } \\
\text { Medicine }\end{array}$ & 77.77 & 88.88 & 90.55 & 89.722 & 88.88 & 85.33 \\
\hline Law & 66.36 & 81.63 & 81.818 & 95 & 86.3636 & 79.4545 \\
\hline $\begin{array}{l}\text { Physical } \\
\text { Education }\end{array}$ & 73.571 & 83.5 & 70 & 84.687 & 88.75 & 79.4375 \\
\hline $\begin{array}{l}\text { Management } \\
\text { \& economic }\end{array}$ & 69.43 & 91.4 & 87 & 99 & 95.5 & 85.2 \\
\hline
\end{tabular}

Table 2. COV for the HUMAN

\begin{tabular}{||c|c||}
\hline HUMAN & COV \\
\hline performance of scientific & 15.670 \\
\hline efficiency of teaching & 11.518 \\
\hline Educational performance & 14.174 \\
\hline Personal behavior & 12.705 \\
\hline Relationship management & 11.281 \\
\hline Final evaluation & 8.310 \\
\hline
\end{tabular}

Table (2): COV for the SCIENTIFIC

\begin{tabular}{||c|c||}
\hline SCIENTIFIC & COV \\
\hline performance of scientific & 32.812 \\
\hline efficiency of teaching & 12.115 \\
\hline Educational performance & 15.298 \\
\hline Personal behavior & 10.421 \\
\hline Relationship management & 15.937 \\
\hline Final evaluation & 10.665 \\
\hline
\end{tabular}


International Journal of Database Management Systems ( IJDMS ), Vol.3, No.3, August 2011

\section{Conclusions}

The study aimed to shed light on the concept of TQM in the evaluation of institutions of higher education by discussing the different intellectual visions that dealt with the overall quality standards and models. Statistical analysis was used for evaluation depending on the standard model to assess the faculty adopted this model to five axes of evaluation. Also the coefficient of variation was used for the comparison between the scientific departments and sections of humanity to know any of the sections where a more homogeneous plate coefficient of variation on each axis and the final value of the evaluation. In this paper found that the College of Veterinary Medicine received the highest percentage for the performance of scientific research, and either the College of Management and Economics got the highest percentage in the axis of the efficiency of teaching of personal conduct and relationship management, and the College of Science got the highest percentage in the educational performance. On average, a final evaluation of the Faculty of Veterinary Medicine received the highest evaluation.

The coefficient of variation in the test found that the performance and efficiency of scientific teaching and educational performance and relationship management more homogeneous in the colleges of humanity, only the personal conduct of scientific faculties more homogeneous.

\section{Appendix A:}

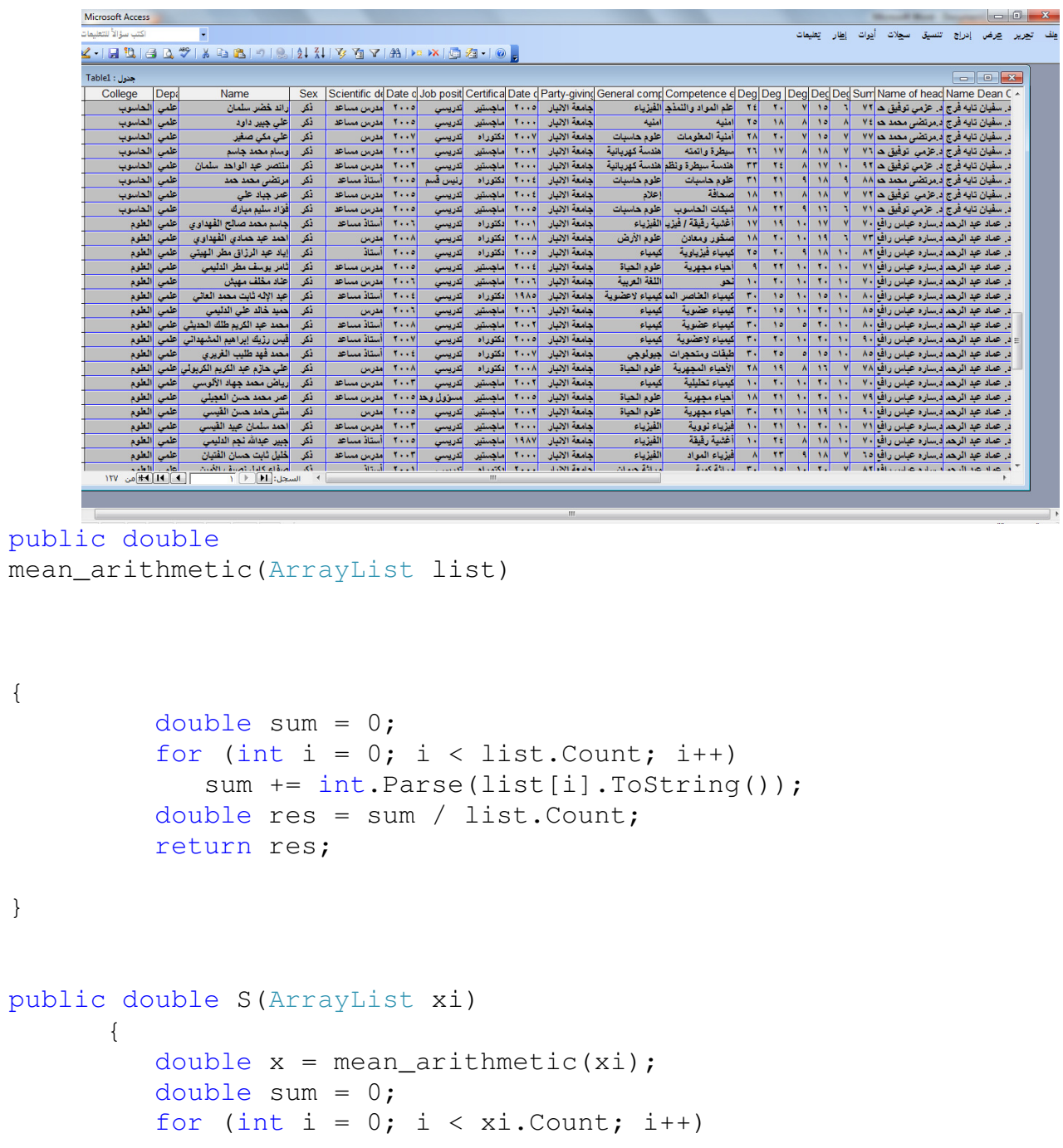


International Journal of Database Management Systems ( IJDMS ), Vol.3, No.3, August 2011

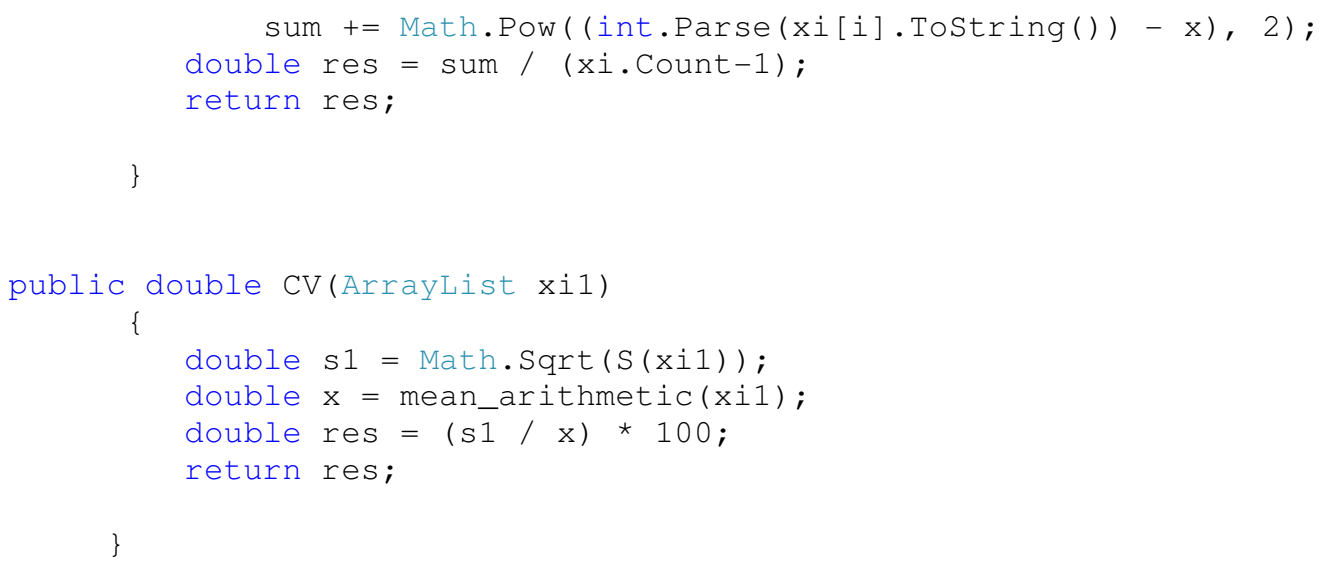

\section{References}

[1] Schwarz, S., \& Westerheijden, D. F. (2007). "Accreditation in the framework of evaluation activities: A comparative study in the European Higher Education Area". Dordrecht: Springer 2007.

[2] Arun S. Patil and Peter J. Gray, "Engineering Education Quality Assurance", CQ University Australia, ISBN 978-1-4419- 0554-3, e-ISBN 978-1-4419-0555-0 DOI 10.1007/9781-4419- 0555-0, Springer Sep (2009).

[3] Jan Kohoutek, "Implementation of the Standards and Guidelines for Quality Assurance In Higher Education in the Central and East-European Countries - Agenda Ahead", ISBN 929069-189-1, UNESCO 2009, Bucharest 2009.

[4] Rizwan Akram Rana, "Dimensions of Quality Assurance in Higher Education: Challenges for Future", University of Glasgow, 2nd International Conference on Assessing Quality in Higher Education, December, 2008.

[5] Adrie J. Visscher, "Improving Quality Assurance in European Vocational Education and Training", Twente University, ISBN 978-1-4020-9526-9, e-ISBN 978-1-4020-95276DOI10.1007/978-1-4020-9527-6,Springer Science+ Business Media B.V. 2009.

[6] G. Gordon Schulmeyer, "Handbook of Software Quality Assurance", ISBN-13: 978-159693186-2,2008 ARTECH HOUSE, INC.

[7] Darwin D. Hendel and Darrell R. Lewis, "Quality Assurance of Higher Education in Transition Countries: Accreditation Accountability and Assessment", Tertiary Education and Management (2005)11:239-258, DOI 10.1007/s11233-005-5111-y, 2005.

[8] Enshun Tian, "On the Tendency of Quality Assurance in Higher Education", School of Management, South-central University for Nationalities,P.R.China,430074, 2006.

[9] Reza Ziarati, "Developing a System of Quality Assurance for the Higher Education Sector in Turkey", Dogus University, 2000.

[10] Ephraim Mhlanga, "Quality Assurance in Higher Education in Southern Africa: The Case of the Universities of the Witwatersrand, Zimbabwe and Botswana", PH.D Thesis, School of Education of the Faculty of Humanities, University of the Witwatersrand, 10th day December, 2008.

[11] ESIB, The National Unions of Students of Europe, "European Student Handbook on Quality Assurance in Higher Education", 2002.

[12] Ferreira, "Chapter4: Quality Models in the Higher Education Sector", University of Pretoria etd, Vol 14 NO 2 2000:182, M (2003). 
International Journal of Database Management Systems ( IJDMS ), Vol.3, No.3, August 2011

[13] Ahmed Ali Maniku, "Higher Education Quality Assurance Policy and Practice in the Maldives: A Case Study From A Small Developing Nation", University of Massey, Palmerstone North, New Zealand, 2008

[14] Bassem Kaissi, Ahmad Jammal, Mohamed Loutfi and Sobhi Abou Chahine, "Quality Assurance for Higher Education in Lebanon Guide I: Introduction to Quality Management in Higher Education", University of Sunderland - UK, Beirut Arab University - Lebanon, Project ID: SCM M014A05, March 2008.

[15] G.Srikanthan, "Developing a Model for Quality in Higher Education", Centre for Management Quality Research, 2002.

[16] EPA "Data Quality Assessment: A Reviewer's Guide", EPA QA/G-9R,United States, Environmental Protection Agency, Office of Environmental Information, Washington, DC 20460, February 2006.

[17] Michael R. Bussieck, Steven P. Dirkse, Alexander Meeraus and Armin Pruessner, "Software Quality Assurance for Mathematical Modeling system ", Springer 2005.

[18] Susan, Jane and Robert, "Statistical Process Control", University of Leeds Business School, ISBN 075065766 9, 2003.

[19] Abdul Ameer, "Data Extraction of Digital Image Using Statistical Analysis", University of Technology, college of Engineering and Science Applled Science Department, October 2006.

Authors

Murtadha Mohammad Hamad received his MSc degree in computer science from University of Baghdad, Iraq. , in 1991, received his $\mathrm{PhD}$ degree in computer science from University of Technology in 2004, and received the Assist Prof. title in 2005. Currently, he is a dean of College of Computer, University of Anbar. His research interested includes DataWarehouse,Software Engineering, and Distributed Database.

Shumos Taha Hammadi graduated from the College of Computer Department of Computer Science University of Anbar, Iraq. Currently, she is master student in the end of preparatory phase.
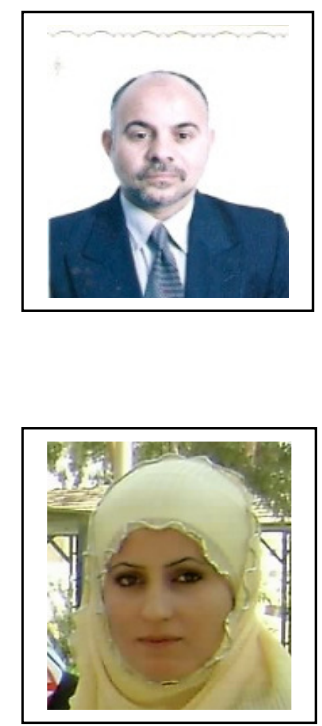